\title{
Kugelberg-Welander Syndrome (Hereditary Proximal Spinal Muscular Atrophy)
}

\author{
J. M. GARVIE,* B.M., M.R.C.P. ; A. L. WOOLF, $\dagger$ M.D., M.R.C.P.
}

Brit. med. F., 1966, 1, 1458-1461

At the 1952 Congress of Scandinavian Neurologists Kugelberg and Welander presented a preliminary report of a heredofamilial syndrome so closely simulating muscular dystrophy of the Duchenne type that all their subjects had previously been diagnosed as suffering from that condition. In 1956 they published their findings, entitling the syndrome heredo-familial juvenile muscular atrophy. Wohlfart et al. (1955), who had been aware of the findings of their colleagues, had been studying the same disease, which they described as hereditary proximal spinal muscular atrophy.

Basically the condition consists initially in a degeneration of the anterior horn cells and motor fibres to the proximal muscles of the limbs involving, first, the large muscles of the buttock and thigh, and later, though not always, the muscles of the upper arm. The face and neck muscles are not affected, but late in the disease the more distal limb muscles may be involved. The signs are therefore of a lower-motor-neurone disorder with weakness, wasting, and loss of the appropriate reflexes, particularly the quadriceps, and, when the arms are involved, initially the triceps and biceps jerks.

Although originally Kugelberg and Welander (1956) described only 12 cases and Wohlfart et al. (1955) only seven, there have since been reports of the condition in many countries other than Sweden. In the U.S.A. it is sufficiently established to appear in a well-known textbook (Ford, 1960). Surprisingly little notice of it has been taken in this country, and so far as we know it has not appeared in the British literature, though cases have no doubt been recognized. As the progress of the condition is very slow, sometimes almost negligible, and the prognosis therefore so different from muscular dystrophy, the distinction between the two diseases is important. We are therefore presenting six cases in two unrelated families in a non-specialized paediatric practice covering a total population of roughly 250,000 .

\section{Family A}

\section{Case 1}

The patient (Fig. 1, II2) walked at the age of 12 months, but his gait was described as always clumsy. At the age of 4 this was noted at the nursery school and confirmed at a local authority orthopaedic clinic, where exercises were prescribed, together with faradism to the quadriceps and general ultra-violet light. At the age of $5 \frac{1}{2}$ he was seen by an orthopaedic surgeon, who suggested a diagnosis of pseudohypertrophic muscular dystrophy and referred him to one of us (J.M. G.) in October 1956. He still had the clumsy, rather waddling gait. He rose from the floor with some difficulty. It was noted that there was no hypertrophy of the calves but that the thighs by comparison were thin, as were the upper arms. The knee-jerks, and to a less extent the ankle-jerks, were diminished.

Three months later he had discovered that he could most easily rise from the floor by turning into the prone position, rising on his hands and feet, and then working his hands up his legs in the manœuvre sometimes associated with the name of Gowers and a

* Consultant Paediatrician, Walsall.

t Consultant Pathologist, Midland Centre for Neurosurgery and Neurology, Smethwick.

classical sign of muscular dystrophy of the Duchenne type. This was at the time thought to be the correct diagnosis.

The boy is now 13 years old-he has gross wasting of the thighs and upper arms (Fig. 2). Although only a year ago he could play cricket, his left leg now tends to give way under him and he prefers to carry a crutch or stick. He is, however, still able to ride a bicycle and augment the family income by selling firewood from a

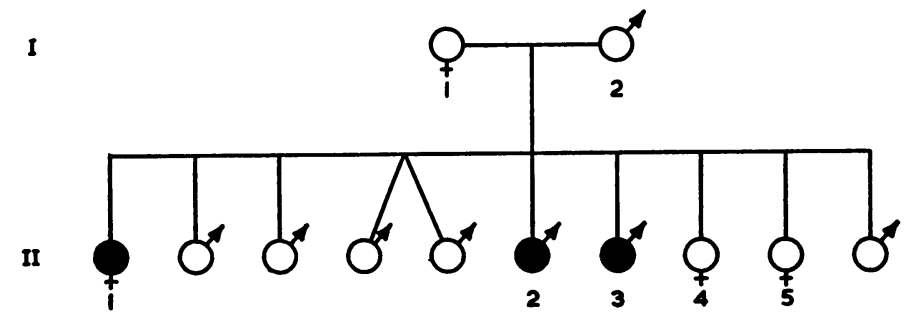

Fig. 1.-Pedigree of Family A. Affected members.

small cart. His quadriceps, biceps, and triceps reflexes are all absent, but an ankle-jerk can be obtained and the supinator reflex is normal. Although comments appeared in the notes from time to time that the progress of the disease was slow, there seemed no reason to doubt the original diagnosis until recently. In March 1964 his serum aldolase was 7.3 Wroblewski units and creatine phosphokinase $53.3 \mu \mathrm{m} . / 1$./ min: international units.

At this time he and his younger brother (Case 2) were seen by one of us (A. L. W.) during a survey of muscular dystrophy in the region, and the correct diagnosis was appreciated for the first time because of the findings made.

Electromyography (6 March) on the right biceps yielded a markedly reduced interference pattern with high-voltage (up to $5 \mathrm{mV}$ ) motor unit action potentials. On 13 April a biopsy specimen was taken from the right flexor digitorum sublimis. The muscle fasciculated after the first specimen was taken. No obvious caps of atrophic muscle fibres were seen, but there was the same accumulation of groups of nuclei consistent with sarcolemmal nuclei and surrounded by fibrous tissue, which was seen in his brother (Case 2) and no doubt represents fasciculi of completely atrophic muscle fibres. In the vicinity of these groups there were also nerve bundles with shrunken perineural nuclei.

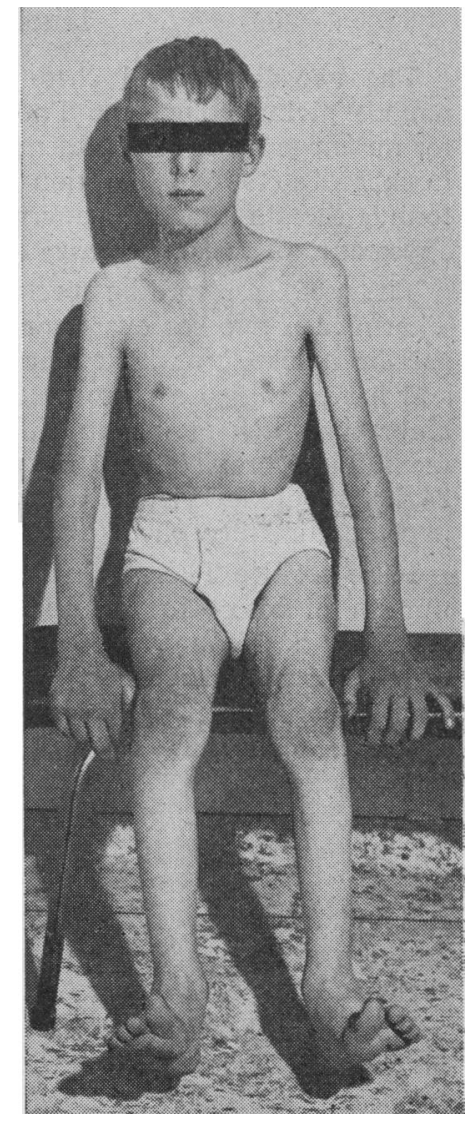

Fig. 2. Case 1. 
These changes were best seen in the transverse section. Vital staining with methylene blue gave a good impregnation of the terminal motor innervation. There were clear examples of re-innervation of denervated muscle fibres by collateral branching, the new plates having an approximately normal form (Fig. 3). There appeared to be a considerable reduction in the number of nerve fibres within the intramuscular nerve bundles. A small cutaneous nerve fixed and stained with osmic acid showed no obvious loss of myelinated nerve fibres. A similar piece fixed in formalin and stained with haematoxylin and eosin also showed no abnormality.

\section{Case 2}

This patient (Fig. 1, II3) is a younger brother (aged 11) of the above patient. He was noticed to have a clumsy gait at the age of 4. When 6 he was referred to an orthopaedic surgeon from his school clinic. He is much more mobile than his brother and can walk a considerable distance, provided he can take his own time. His thigh muscles show some wasting and knee-jerks are absent Ankle-jerks are present. There is some wasting of his upper arms, and his biceps and triceps jerks are diminished. He also rises from the floor by means of Gowers's manœuvre. When he was first seen at a paediatric clinic there was no hesitation in regarding him as a case of the Duchenne type of muscular dystrophy. At that time his older brother was attending the same clinic, but his mother denied that she had any other affected children, only later beginning to worry about her oldest daughter. In March 1964 his serum aldolase was 4.5 Wroblewski units and creatine phosphokinase 36.7 I.U./1.

Electromyography (6 March) on the right biceps yielded a trace with high-voltage motor unit action potentials (up to $2 \mathrm{mV}$ ).

A biopsy specimen was taken from the right flexor carpi radialis on 13 April. It was noted that the muscle fasciculated after the first specimen was taken. The transverse section showed that while the majority of fasciculi contained normal-looking muscle fibres of apparently normal size many of these were capped by fasciculi consisting only of extremely atrophic but otherwise normal-looking muscle fibres (Fig. 4). There were also some accumulations in the adjacent fibrous tissue of small ovoid or round nuclei which were probably originally sarcolemmal nuclei. Almost all evidence of their muscle fibres had disappeared, though in the neighbourhood of one group a faint trace of striated tissue could be seen. In longitudinal section the atrophic muscle fibres were less conspicuous, as, because of their narrow diameter, they rapidly passed out of the plane of section. However, there was no difficulty in finding them.
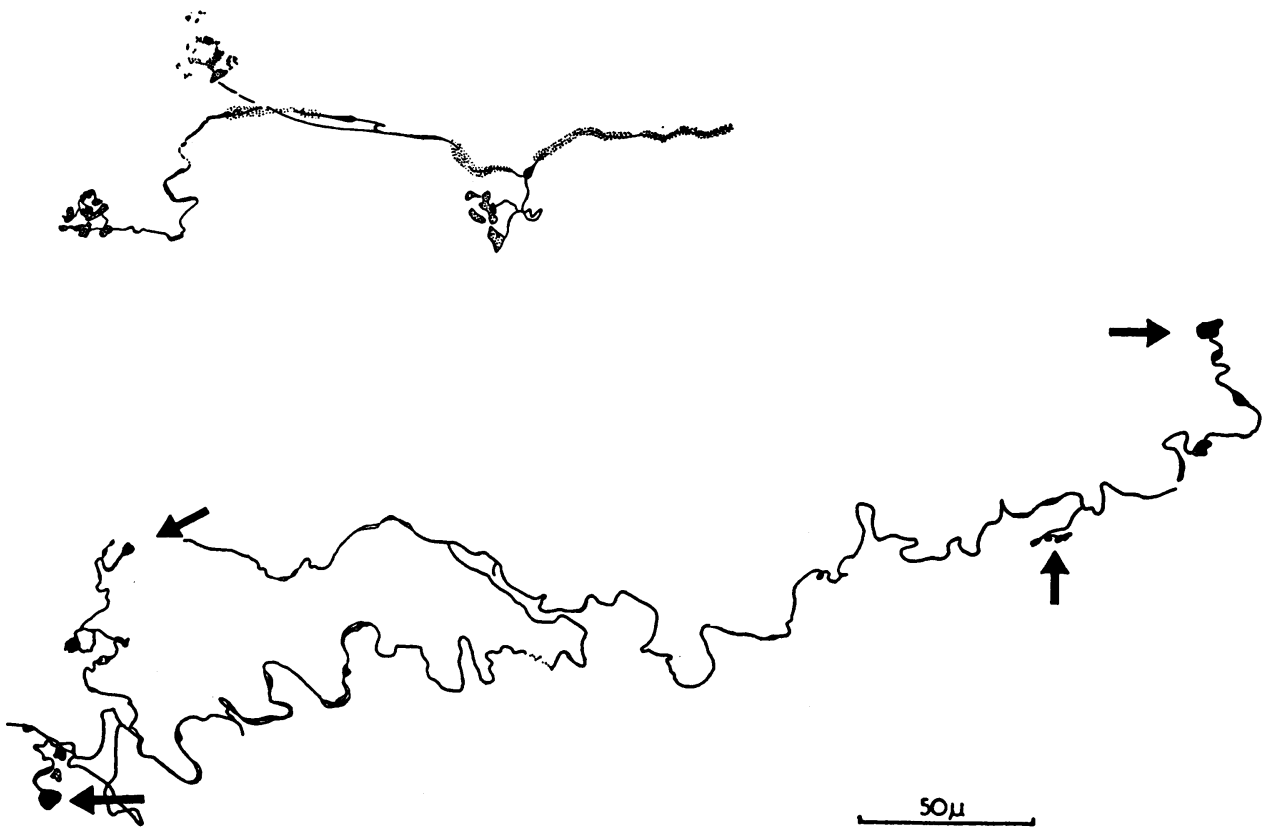

FIG. 3.-Case 1. Intramuscular nerve endings. Upper drawing shows collateral re-innervation-that is, three normal-looking motor end-plates arise from a single subterminal nerve fibre. In lower drawing four poorly formed end-plates (arrows) arise from a single fibre. Vital staining with methylene blue.
Vital staining with methylene blue showed an apparent reduction in the number of nerve fibres in the intramuscular nerve bundles, although those remaining had a normal appearance. The subterminal nerve fibres tended to wander excessively across the muscle fibres. In some areas, apparently in association with the atrophic muscle fibres, there were large numbers of coarsely beaded nerve fibres wandering along the muscle fibres. A small cutaneous nerve fixed and stained in osmic acid showed no obvious loss of myelinated nerve fibres, nor was there any abnormality in a similar specimen fixed in formalin and stained with haematoxylin and eosin.

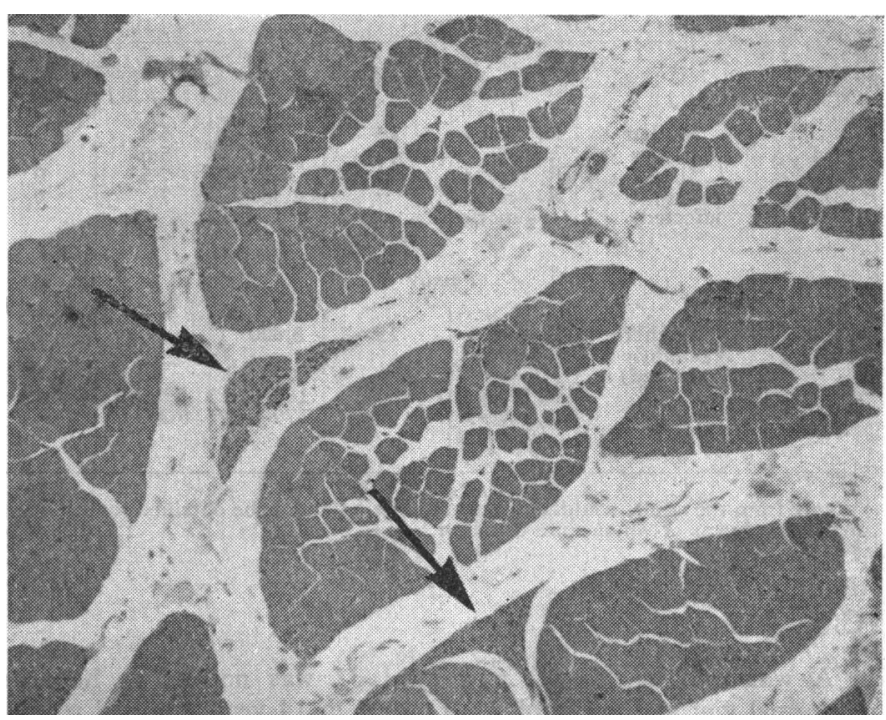
Fig. 4.-Case 2. Transverse section of muscle, showing much fat be-
tween fasciculi and "caps" of extremely atrophic muscle fibres (arrows). (Haematoxylin and eosin.)

\section{Case 3}

This patient (Fig. 1, II1) is the eldest sister (aged 22) of the above patients. Until recently she was a hostess at a holiday camp. She now works in a factory and leads a normal social life; she can play tennis and enjoy dancing. Since the age of about 14 she has realized that she cannot rise from the floor without some difficulty, and for three to four years her legs have been liable to give way under her so that she falls to the ground. When first seen in 1964 her knee-jerks were found to be absent and her ankle-jerks to be present and quite brisk. Her feet were short and rather broad; there were no other abnormal findings.

Electromyography ( 30 June) on the right rectus femoris yielded a trace with markedly reduced interference pattern and high-voltage motor unit action potentials. Five potentials were available for analysis. The average voltage was $2,660 \mu \mathrm{V}$ (normal 370-840 $\mu \mathrm{V})$ and the average duration was 7 msec. (normal 6.2-9.6 msec.). A trace from the right biceps showed a slightly reduced interference pattern. Twenty-three potentials were available for analysis. The average voltage was $510 \mu \mathrm{V}$ (normal $180-520 \mu \mathrm{V}$ ) and the average duration $7.5 \mathrm{msec}$. (normal $5.5-7.9$ m.sec.).

\section{Other Members of Family}

Apart from the affected siblings, both parents and two younger sisters (Fig. 1, II, 4 and 5) have been examined clinically and electromyographically, and are normal (see Table). Two of the boys (aged 3 and 16) are clinically normal. The three other boys have not been seen, two being 
away at work and one on active service in the Middle East. It is unlikely that any of these are affected, even mildly, and the lastmentioned is a keen amateur boxer.

Recognition of the correct diagnosis in this family led us to reconsider another family originally seen and partially investigated in 1962.

\begin{tabular}{|c|c|c|c|c|c|c|}
\hline \multicolumn{2}{|c|}{ Electromyographic } & \multicolumn{2}{|l|}{ Analysis } & \multicolumn{3}{|c|}{ Unit Action Potentials } \\
\hline Case & $\begin{array}{l}\text { Relationship to } \\
\text { Affected Mem- } \\
\text { bers of Family }\end{array}$ & Muscle & $\begin{array}{l}\text { No. of } \\
\text { Potentials } \\
\text { Analysed }\end{array}$ & $\begin{array}{l}\text { Average } \\
\text { Voltage } \\
(\mu \mathrm{V})\end{array}$ & $\begin{array}{c}\text { Average } \\
\text { Duration } \\
\text { (msec.) }\end{array}$ & $\begin{array}{l}\text { Poly- } \\
\text { phasic }\end{array}$ \\
\hline
\end{tabular}

\begin{tabular}{|c|c|c|c|c|c|c|}
\hline \multicolumn{7}{|c|}{ Family $A$} \\
\hline $\begin{array}{r}\text { I } 1 \\
\text { I } 2 \\
\text { II } 1\end{array}$ & $\begin{array}{l}\text { Mother } \\
\text { Father } \\
\text { Sister } \\
\text { (slightly } \\
\text { affected) }\end{array}$ & $\begin{array}{l}\text { R. biceps } \\
\text { R. b’ } \\
\text { R. rectus } \\
\text { remoris }\end{array}$ & $\begin{array}{r}23 \\
26 \\
23 \\
5\end{array}$ & $\begin{array}{r}230 \\
253 \\
510 \\
2,660\end{array}$ & $\begin{array}{l}5 \cdot 9 \\
5 \cdot 6 \\
7.5 \\
7\end{array}$ & $\begin{array}{l}4 \\
0 \\
0 \\
0\end{array}$ \\
\hline \multicolumn{7}{|c|}{ Family $B$} \\
\hline $\begin{array}{l}\text { Normal } \\
\text { cases }\end{array}$ & $\begin{array}{l}\text { Mother } \\
\text { (slightly } \\
\text { affected) }\end{array}$ & $\begin{array}{c}\text { R. rectus } \\
\text { femoris } \\
\text { R. biceps } \\
\begin{array}{c}\text { R. rectus } \\
\text { femoris }\end{array}\end{array}$ & 15 & $\begin{array}{l}3,800 \\
\\
180-520 \\
370-840\end{array}$ & $\begin{array}{c}9 \\
\\
5 \cdot 5-7 \cdot 9 \\
6 \cdot 2-9 \cdot 6\end{array}$ & $\begin{array}{r}7 \\
0-16\end{array}$ \\
\hline
\end{tabular}

Only from the adults could sufficient discrete potentials be obtained for statistical analysis in terms of voltage and duration.

\section{Case 4}

A woman (Fig. 5, I1) now aged 32 was noticed to have an abnormal gait at the age of 2 . From 4 to 14 years she had regular physiotherapy, which she thinks did not influence her disability.

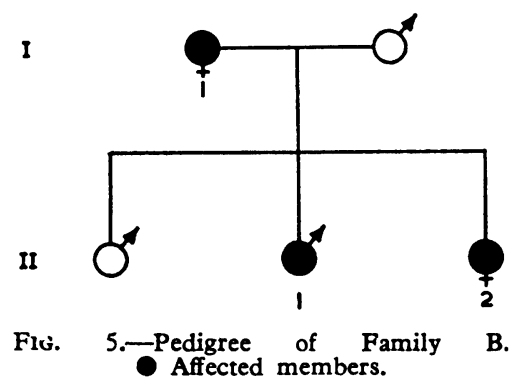

This is minimal, and now, 30 years after the onset, she is able to do all her shopping and housework, including rearing a young family, without undue tiredness. She has, however, never been able to run or jump or go upstairs with any ease. She was not unduly worried when her second child showed similar signs to hers, and her main concern was that his childhood should not be spoilt, as she maintained hers had been, by regular attendance at physiotherapy clinics. She has a slightly waddling gait with prominent buttocks and marked lumbar lordosis. Her knee-jerks are absent. All the other tendon reflexes, including ankle-jerks, are present. Her feet are rather short and wide, and she has always needed a broadfitting shoe.

Electromyography on the right rectus femoris on 23 July 1964 showed a reduced interference pattern with high-voltage longduration motor unit action potentials (Fig. 6). Fifteen potentials were available for analysis. The average voltage was $3,800 \mu \mathrm{V}$ and the average duration $9 \mathrm{msec}$; $7 \%$ were polyphasic. A muscle biopsy specimen was taken from the right vastus internus on 13 August. The exposed muscle appeared very fatty.

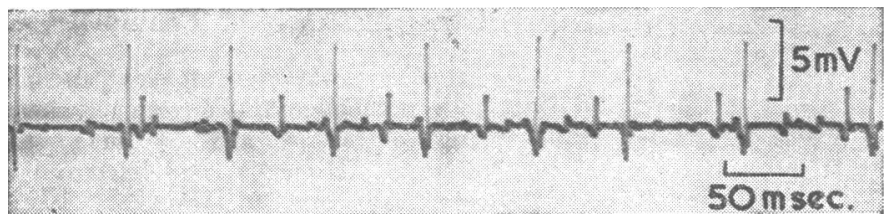

FIG. 6.-Case 4. Electromyographic trace from the right rectus femoris. There are discrete very-high-voltage motor unit action potentials (neuropathic trace).
Staining with haematoxylin and eosin showed that the fasciculi were separated by narrow strips of fat, and in transverse section showed considerable variance in the diameter of the muscle fibres, some fasciculi containing fibres much larger than normal-though with an occasional slender fibre-while others contained fibres a little narrower than usual. The fibres in these fasciculi had a looser arrangement than the others. Cholinesterase preparations showed that most of the subneural apparatuses had a normal appearance, but there were occasional single elements by themselves or at a little distance from the rest of the elements in the apparatus to which they obviously belonged. Vital staining with methylene blue showed a paucity of intramuscular nerve fibres, those present tending to

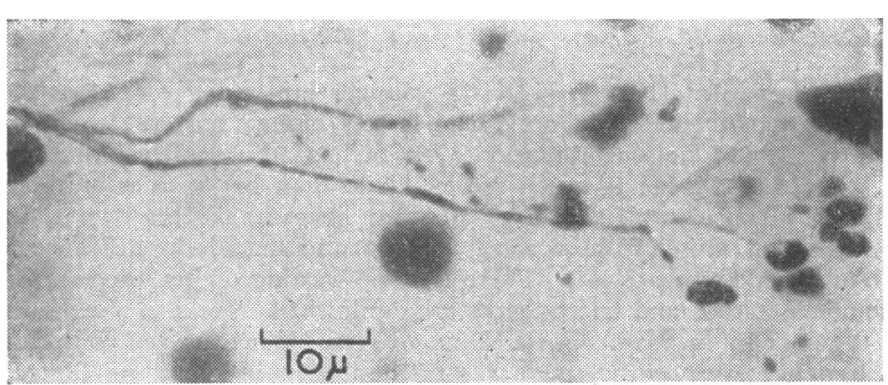

Fig. 7.-Case 4. Attenuated subterminal nerve fibre with very delicate terminal arborization and small rounded terminal expansions. Vital staining with methylene blue.

become unduly slender towards their termination, sometimes ending in a delicate and expanded terminal arborization with diminutive terminal expansions (Fig. 7).

The first child, aged 9, is clinically normal, and electromyography on the right rectus femoris yielded a normal trace.

\section{Case 5}

The second boy (Fig. 5, II1), now aged $4 \frac{1}{2}$, was first seen at the age of $2 \frac{1}{2}$ years. He stood with support at 12 months, coasted round the furniture at 14 months, but could not walk without support until 21 months. He had a markedly waddling gait with exaggerated lordosis. There was some weakness of the extensors of the hip and he had difficulty in rising from the floor, though he did not use the full Gowers's manœuvre. His knee-jerks were present, though weak. His ankle-jerks were normal. His arms were unaffected. By the age of $4 \frac{1}{2}$ his knee-jerks could no longer be obtained. In December 1962 his serum aldolase was 6.85 Wroblewski units and creatine phosphokinase 0.551 unit (Schapira et al., 1960) (both normal). Electromyography in December 1962 on the right deltoid showed no abnormality, but a record in July 1964 on the right rectus femoris showed a markedly reduced interference pattern with discrete high-voltage $(7.5 \mathrm{mV})$ motor unit action potentials.

\section{Case 6}

This girl (Fig. 5, II2), aged 2, was able to stand holding on at 11 months and walked unsupported at 18 months. When first seen at this age her knee-jerks were present, but like her mother and older brother she can neither run nor jump, nor can she climb stairs with any facility. Electromyography (30 July 1964) on the right rectus femoris yielded discrete potentials of moderately high voltage $(660 \mu \mathrm{V})$.

\section{Discussion}

The clinical picture, the normal or near-normal enzyme levels, the biopsy studies, and the electromyography findings leave no doubt that the disorder described is a neuropathy and not a myopathy. The cases fit the description of Kugelberg and Welander in every way.

Dubowitz (1964), under the title "infantile muscular atrophy," described the cases of two children from each of two families suffering from a muscular atrophy of slow progression. 
The children in the first family resemble our Cases 1, 2, 5, and 6. We feel that the term "infantile muscular atrophy" is not an appropriate description and may indeed be disadvantageous in distracting attention from the fact that the disease can present in adolescence.

Kugelberg and Welander (1956) maintained that the condition they described was inherited in a non-sex-linked recessive manner, and this has been generally accepted since. Spira (1963), while concurring, commented on the apparent massive penetrance of the gene in that four out of five and three out of five siblings were affected in the two families he described. This he attributed to the fact that the parents in both families were first cousins. Magee and De Jong (1960), however, described a family typical of the Kugelberg-Welander syndrome, but in which inheritance was apparently by a simple dominant, a mother and two children being affected. This would appear to be the situation also in Family B. It is interesting that both in this family and that of Magee and De Jong the disease had been apparently static in the adults affected for 30 years or more.

A feature of previously described cases has been the frequency with which they have been diagnosed as suffering from the Duchenne type of muscular dystrophy. Since we presented our findings at a paediatric meeting last October correspondence has revealed that other cases were masquerading under the same erroneous diagnosis. This mistake was made in the first two cases seen in Family A. It was appreciated from the onset that the condition in Family B, though initially undiagnosed, had a neurogenic basis.

Confusion between the two conditions is easy, since they have many common features. In both the child may be brought because he has an unusual gait or because he cannot easily rise from the ground or climb stairs. Both are heredo-familial. In both there is an exaggerated lordosis, and weakness and wasting of the proximal muscles of the legs, and therefore both employ Gowers's manœuvre to rise from the floor. Both have diminished or absent knee-jerks, and in both the shoulder-girdle may eventually be involved. In neither is there any sensory loss or obvious impairment of intelligence. As Kugelberg and Welander (1956) point out, the wasting of the thigh muscles may give a spurious impression of hypertrophy of the calves. At one time an obviously erroneous note to this effect was made in the records of Case 2.

In the Kugelberg-Welander syndrome there is a wider scatter in the age of onset, from 1 to 17 years, but though some cases present only in the middle or late teens abnormalities are often noted under 5 , as in muscular dystrophy. If one is faced with a boy a few years old who shows the symptoms and signs mentioned there may be nothing whatever to suggest that he is not a case of muscular dystrophy of the Duchenne type. As the years pass one may be pleasantly surprised by the very slow or negligible deterioration, but by then the diagnosis may have become an idée fixe.

Fasciculation should differentiate a primary neuronal degeneration from a myopathy. It was not observed in any of these cases except the first two under the stimulus of cutting the nerve bundles at muscle biopsy. Neostigmine provocation was not attempted. Some textbooks lead one to believe that fasciculation may occasionally occur in a myopathy. Thus, for example, referring to the Duchenne type of muscular dystrophy "muscular fasciculation is usually absent" (Brain, 1962). In the absence of denervation fasciculation is not to be expected, and, as Kugelberg and Welander (1956) point out, it is probable that cases recorded in the older literature as muscular dystrophy with fibrillar twitching (Scheiffarth, quoted by Wohlfart and Eliasson, 1955) or muscular dystrophy with anterior-horn changes (Ballet and Laignel-Lavastine, 1908) were in reality examples of the Kugelberg-Welander syndrome. Now that the newer techniques of muscle biopsy and electromyography make the distinction easier a clearer picture of both conditions should emerge.

Provided the possibility is borne in mind, they can easily be differentiated in early childhood by estimation of the serum aldolase and creatine phosphokinase, which are markedly elevated in muscular dystrophy. The differential diagnosis is not merely academic, as patients with the Kugelberg-Welander syndrome have a normal life expectancy. A much better prognosis can therefore be given which will relieve some of the anxiety of their parents. Furthermore, as the hands are usually not seriously affected even when leg function is very poor, appropriate vocational training may be a most important part of the child's management.

\section{Summary}

Five cases of hereditary proximal spinal muscular atrophy are described, together with the findings on electromyography and muscle biopsy. The close clinical resemblance to the Duchenne type of muscular dystrophy is discussed and it is suggested that this may lead to misdiagnosis and a worse prognosis than should be given. Attention is also drawn to the recently described cases of infantile muscular atrophy of slow progression, and the suggestion is made that, for the time being at least, a distinction should be maintained between these and the condition described by Kugelberg and Welander, in which the onset may be as late as adolescence and only exceptionally occurs in infancy.

Our thanks are due to Mr. G. Gasser for photographic assistance.

\section{REFERENCES}

Ballet, G., and Laignel-Lavastine (1908). Encéphale, 3, 229. Quoted by Kugelberg and Welander (1956).

Brain, Lord (1962). Diseases of the Nervous System, 6th ed., p. 738. Oxford Univ. Press, London.

Dubowitz, V. (1964). Brain, 87, 707.

Ford, F. R. (1960). Diseases of the Nervous System in Infancy, Childhood, and Adolescence, 4th ed., p. 389. Thomas, Springfield, Illinois. Kugelberg, E., and Welander, L. (1956). Arch. Neurol. Psychiat. (Chic.),

Magee, K. R., and De Jong, R. N. (1960). Arch. Neurol. (Chic.), 2, 677.

Schapira, F., Dreyfus, J.-Cl., Schapira, G., and Demos, J. (1960). Rev. franc Etud. clin. biol., 5, 990.

Spira, R. (1963). Confin. neurol. (Basel), 23, 245 Wohlfart, G., Fex, J., and Eliasson, S. (1955). Acta psychiat. Scand., 30, 